\title{
Mangiferin positively regulates osteoblast differentiation and suppresses osteoclast differentiation
}

\author{
YUUSUKE SEKIGUCHI, HIROSHI MANO, SACHIE NAKATANI, JUN SHIMIZU, AYA KATAOKA, \\ KANA OGURA, YOSHIFUMI KIMIRA, MIDORI EBATA and MASAHIRO WADA \\ Department of Clinical Dietetics and Human Nutrition, Faculty of Pharmaceutical Sciences, Josai University, \\ Sakado, Saitama 350-0295, Japan
}

Received December 14, 2016; Accepted May 3, 2017

DOI: $10.3892 / \mathrm{mmr} .2017 .6752$

\begin{abstract}
Mangiferin is a polyphenolic compound present in Salacia reticulata. It has been reported to reduce bone destruction and inhibit osteoclastic differentiation. This study aimed to determine whether mangiferin directly affects osteoblast and osteoclast proliferation and differentiation, and gene expression in MC3T3-E1 osteoblastic cells and osteoclast-like cells derived from primary mouse bone marrow macrophage cells. Mangiferin induced significantly greater WST-1 activity, indicating increased cell proliferation. Mangiferin induced significantly increased alkaline phosphatase staining, indicating greater cell differentiation. Reverse transcription-polymerase chain reaction (RT-PCR) demonstrated that mangiferin significantly increased the mRNA level of runt-related transcription factor 2 (RunX2), but did not affect RunX1 mRNA expression. Mangiferin significantly reduced the formation of tartrate-resistant acid phosphatase-positive multinuclear cells. RT-PCR demonstrated that mangiferin significantly increased the mRNA level of estrogen receptor $\beta(\mathrm{ER} \beta)$, but did not affect the expression of other osteoclast-associated genes. Mangiferin may inhibit osteoclastic bone resorption by suppressing differentiation of osteoclasts and promoting expression of ER $\beta$ mRNA in mouse bone marrow macrophage cells. It also has potential to promote osteoblastic bone formation by promoting cell proliferation and inducing cell differentiation in preosteoblast MC3T3-E1 cells via RunX2. Mangiferin may therefore be useful in improving bone disease outcomes.
\end{abstract}

\footnotetext{
Correspondence to: Dr Yuusuke Sekiguchi, Department of Clinical Dietetics and Human Nutrition, Faculty of Pharmaceutical Sciences, Josai University, 1-1 Keyakidai, Sakado, Saitama 350-0295, Japan E-mail: sekiguti@josai.ac.jp
}

Key words: mangiferin, osteoblast, osteoclast, runt-related transcription factor 2 , estrogen receptor $\beta$

\section{Introduction}

Mangiferin (MGF) is a naturally occurring polyphenolic compound commonly present in Mangifera indica and Salacia reticulata $(1,2)$. MGF has a variety of pharmacological effects, including antiviral and an antioxidant activity $(3,4)$. There have been a number of studies that have used MGF and $S$. reticulata for the treatment of diabetes mellitus; MGF and $S$. reticulata reportedly inhibit the activity of $\alpha$-glucosidase and suppress the mRNA expression of fructose-1,6-bisphosphatase and glucose-6-phosphatase $(5,6)$. The effects of MGF and $S$. reticulata on bone and cartilage disease have also been reported; $S$. reticulata leaf ameliorated the symptoms of rheumatoid arthritis (RA) by reducing bone tissue destruction in type II collagen antibody-induced arthritic mice (7). Furthermore, a previous study reported that MGF inhibits osteoclastic differentiation of RAW 264.7 cells (8).

Osteoblasts and osteoclasts have critical roles in bone tissue; bone metabolism is maintained by the balance of bone formation by osteoblasts and bone resorption by osteoclasts. Osteoblast- and osteoclast-associated bone diseases include osteoporosis, osteopetrosis and RA (9-11). RA is also a chronic inflammatory disease, characterized by inflammatory cell infiltration, synovial hyperplasia, and destruction of cartilage and bone (12-14); this bone tissue destruction is induced and promoted by osteoclast activation (15). In addition, osteoblasts produce receptor activator nuclear factor- $\mathrm{\kappa} B$ ligand (RANKL) as an osteoclast differentiation factor (16).

RA treatment is currently primarily based on the administration of anti-inflammatory drugs, immunosuppressive drugs and antibody medicines (17-19); calcium, steroids and bisphosphonates have also been used to treat the deconstruction of bone (20-22). In addition, bone resorption can be suppressed and bone formation can be enhanced by estrogen receptors, such as estrogen receptor- $\alpha(\operatorname{ER} \alpha)$ and ER $\beta$ (23).

It was previously reported that the leaf of $S$. reticulata ameliorated the symptoms of arthritis in a mouse model of RA, and suppressed cell proliferation and gene expression of matrix metalloproteinase 3, RANKL, cathepsin K and c-fos mRNA in murine synovial cells derived from mice with RA (8). This improvement in RA symptoms was potentially associated with the MGF contained in S. reticulata. The present study examined whether MGF directly affects osteoblast and osteoclast 
proliferation and differentiation. It was aimed to investigate whether MGF affects cell proliferation, cell differentiation, and gene expression in cultured osteoblasts and osteoclasts.

\section{Materials and methods}

Ethics statement. The use of experimental animals was approved, and this study was performed in accordance with the National Institute of Health $(\mathrm{NIH})$ Guide for the Care and Use of Laboratory Animals and the Institutional Animal Care and Use Committee of Josai University (permit no. H22064; Saitama, Japan).

Cell and culture conditions. MC3T3-E1 cells were purchased from RIKEN Cell Bank (RIKEN BioResource Center, Tsukuba, Japan). The cells were cultured in $\alpha$-minimal essential medium (MEM; Gibco; Thermo Fisher Scientific, Inc., Waltham, MA, USA) supplemented with $10 \%$ fetal bovine serum (Invitrogen; Thermo Fisher Scientific, Inc.) and penicillin $(50 \mathrm{IU} / \mathrm{ml})$. Cells were subcultured every 2 nd day using trypsin/EDTA (Sigma-Aldrich; Merck KGaA, Darmstadt, Germany), and were maintained at $37^{\circ} \mathrm{C}$ in a humidified atmosphere of $5 \% \mathrm{CO}_{2}$ and $95 \%$ air.

Osteoclast-like cells (OCL) were derived from the bone marrow of three 8-week-old ddY male mice (Tokyo Laboratory Animals Science. Tokyo. Japan). Bone marrow macrophage (BMM) cells were prepared immediately from the femur and tibia of ddY mice. The BMM cells were induced by macrophage colony stimulating factor (M-CSF) from bone marrow cells. Cell suspensions were plated at $1 \times 10^{4}$ cells/well in a 96-well plate in $\alpha$-MEM containing $10 \% \mathrm{FBS}$, penicillin, and supplemented with M-CSF (20 ng/ml) and RANKL (10 ng/ml) to induce osteoclast differentiation. The cells were cultured as described previously (24).

Cell proliferation assay. MC3T3-E1 cells were plated in 96-well microplates (BD Biosciences, Franklin Lakes, NJ, USA) at a density of $3 \times 10^{3}$ cells/well. After $24 \mathrm{~h}$ of incubation, MGF $\left(1 \times 10^{-3}, 10^{-4}, 10^{-5}, 10^{-6}\right.$ and $\left.10^{-7} \mathrm{M}\right)$ dissolved in dimethyl sulfoxide was mixed in the culture medium and added to each well. The control group was treated with medium only. After $2 \mathrm{~h}$, the cell proliferation reagent WST-1 (Roche Diagnostics, Indianapolis, IN, USA) was added to each well (1/10 volume of the previously added medium), and the plates were incubated for $30 \mathrm{~min}$. Cell proliferation was then measured at $450 \mathrm{~nm}$ using a spectrophotometer (Wallac 1420ARVO.SX multilabel counter; PerkinElmer, Inc., Waltham, MA, USA). All experiments were performed in triplicate with independent samples.

Alkaline phosphatase (ALP) activity. After 21 days of treatment with MGF, MC3T3-E1 cells were fixed with $100 \%$ methanol. The fixed cells were incubated in ALP staining solution for $20 \mathrm{~min}$ at $37^{\circ} \mathrm{C}$; the ALP staining solution consisted of 0.05 M AMP buffer at pH 9.8, $10 \mathrm{mM}$ naphthol AS-BI phosphate (Sigma-Aldrich; Merck $\mathrm{KGaA}$ ), and $1 \mathrm{mM}$ fast red violet LB salt (Sigma-Aldrich; Merck KGaA). The ALP stained areas were then inspected using a light microscope (Penguin 600CL; Pixera Corporation, Tokyo, Japan). The ALP activity was quantified by densitometric analysis using ImageJ software (version 1.3; National Institutes of Health, Bethesda,
MD, USA). All experiments were performed in triplicate with independent samples.

Tartrate-resistant acid phosphatase (TRAP) activity. After 6 days of culture, the OCL were fixed with $100 \%$ methanol. The fixed cells were incubated in the presence of $\mathrm{L}(+)$-tartrate buffer $(0.335 \mathrm{~mol} / \mathrm{l}, \mathrm{pH} 4.9 \pm 0.1)$ with a TRAP kit (Sigma-Aldrich; Merck KGaA) for $5 \mathrm{~min}$ at $37^{\circ} \mathrm{C}$. Following staining, TRAP stained areas were inspected using a light microscope (Penguin 600CL). TRAP-positive cells containing three or more nuclei were counted as multinuclear osteoclasts. The TRAP activity was quantified by densitometric analysis using ImageJ software. All experiments were performed in triplicate with independent samples.

RNA extraction and reverse transcription-polymerase chain reaction (RT-PCR). Total RNA from MC3T3-E1, BMM and OCL were extracted from the cultures using TRIzol reagent, and RNA was extracted according to the manufacturer's protocol (Invitrogen; Thermo Fisher Scientific, Inc.). cDNA was prepared from $1 \mu \mathrm{g}$ total RNA using the SuperScript First-Strand Synthesis system for RT-PCR (Invitrogen; Thermo Fisher Scientific, Inc.). Amplification was performed in $10 \mu \mathrm{l}$ of reaction mixture containing $1 \mu \mathrm{l}$ cDNA using EX Taq (Takara Bio, Inc., Otsu, Japan). The primer sequences used for each PCR are outlined below. Initial denaturation was performed at $94^{\circ} \mathrm{C}$ for $30 \mathrm{sec}$, annealing temperatures ranged from $58-62^{\circ} \mathrm{C}$ for $30 \mathrm{sec}$, and extension was done at $72^{\circ} \mathrm{C}$ for $3 \mathrm{~min}$. A final extension was performed at $72^{\circ} \mathrm{C}$ for $3 \mathrm{~min}$. PCR cycles varied from 20-60 cycles, due to certain genes, particularly RANK and cathepsin $\mathrm{K}$, exhibiting multiple variations and therefore requiring further cycles in order to confirm gene expression.

Primers were as follows: Cathepsin K, 5'-CCAGTGTGG TTCCTGTTGG-3' (forward) and 5'-TTGCCGTGGCGT TATACAT-3' (reverse); ER $\alpha, 5^{\prime}$-AATTCTGACAATCGA CGCCAG-3' (forward) and 5'-GTGCTTCAACATTCTCCC TCCTC-3' (reverse); ER $\beta$, 5'-CAAGCTCATCTTTGCTCC AG-3' (forward) and 5'-GCAGATGTTCCATGCCCTTG-3' (reverse); nuclear factor of activated T-cells, cytoplasmic 1 (NFATc1), 5'-CACCAAAGTCCTGGAGATCC-3' (forward) and 5'-GAAACGCTGGTACTGGCTTC-3' (reverse); NF- $\kappa$ B, 5'-GCTTTGCAAACCTGGGAATA-3' (forward) and 5'-TCC GCCTTCTGCTTGTAGAT-3' (reverse); RANK, 5'-CCA GGGGACAACGGAATCAG-3' (forward) and 5'-GGCCGG TCCGTGTACTCATC-3' (reverse); osteoclast-associated receptor (OSCAR), 5'-TGTTCTGGAACTGCTGGTAACG-3' (forward) and 5'-GATGAGGTTTCCCTGGGTATAG-3' (reverse); runt-related transcription factor 1 (RunX1), 5'-GGT CGTTGAATCTCGCTACC-3' (forward) and 5'-ACTTCC TCTGCTCCGTGCTA-3' (reverse); RunX2, 5'-ACACCTACT CTCATACTGGGATGAGGAATG-3' (forward) and 5'-ATG GTGGAGATCATCGCGGACCACCCGGCC-3' (reverse); GAPDH, 5'-TTGACCTCAACTACATGG-3' (forward) and 5'-CAGGGTGGTGGACCTCAT-3' (reverse).

The PCR products were separated on $2 \%$ agarose gel with Tris-acetate-EDTA buffer and visualized with ethidium bromide. All gels were digitally imaged and the band intensities of these digital images were determined using ImageJ software. Each mRNA level was normalized against the GAPDH mRNA level. All data are presented as the fold change 

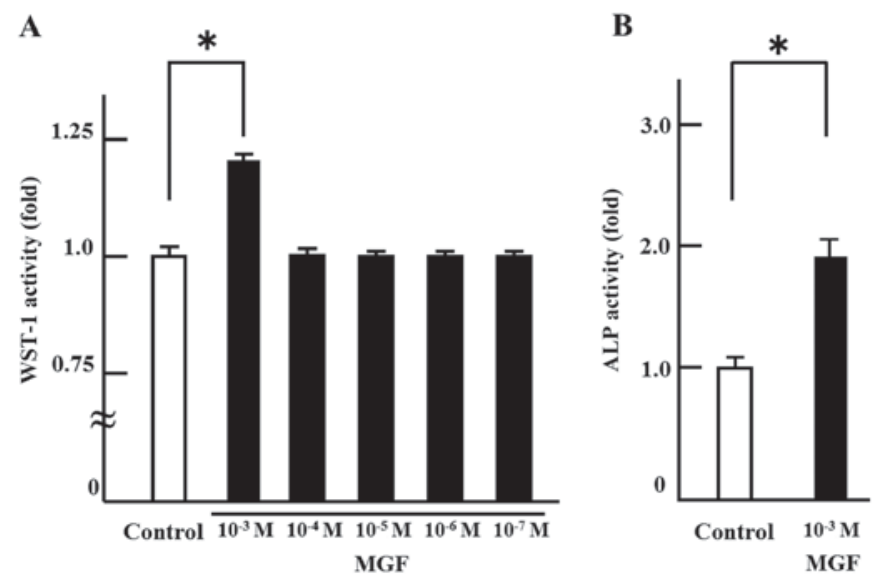

Figure 1.Effects of MGF on cell proliferation and differentiation of MC3T3-E1 cells. (A) MC3T3-E1 cells were treated with or without MGF. After $2 \mathrm{~h}$ of incubation, cell proliferation was measured by WST-1. (B) MC3T3-E1 cells were treated with or without MGF. After 21 days of incubation, the cells were subjected to ALP staining. The results are expressed as the mean \pm standard deviation of three independent experiments $(n=3)$. "P $<0.05$. MGF, mangiferin; ALP, alkaline phosphatase.

in the target/GAPDH ratio. All experiments were performed in triplicate with independent samples.

Statistical analysis. All experiments were performed with triplicate independent samples and were repeated at least three times, giving qualitatively identical results. Statistical analysis was carried out with Stat-Mate III version 3.18 (ATMS Co., Ltd., Tokyo, Japan). Data were analyzed using the Student's t-test, with $\mathrm{P}<0.05$ considered to indicate a statistically significant difference.

\section{Results}

Effects of mangiferin on cell proliferation, cell differentiation and gene expression regulation of MC3T3-E1 cells. In order to investigate the effect on cell proliferation, MGF was added at concentrations ranging from $10^{-3} \mathrm{M}$ to $10^{-7} \mathrm{M}$. There was no change in cell proliferation with MGF at concentrations of $10^{-4} \mathrm{M}$ to $10^{-7} \mathrm{M}$ compared with the control. Only $10^{-3} \mathrm{M}$ MGF resulted in an increase in WST-1 activity; $10^{-3} \mathrm{M}$ MGF induced $>20 \%$ cell proliferation of MC 3T3-E1 cells compared with controls (Fig. 1A). Thus, $10^{-3} \mathrm{M}$ MGF was selected for use in the subsequent experiments. In order to investigate the effect of MGF on cell differentiation, ALP staining was performed. MGF induced an $\sim 2$-fold increase in the ALP-stained area of MC 3T3-E1 cells compared with controls (Fig. 1B). Regarding the effect of MGF on the expression of genes involved in the differentiation of osteoblasts, MGF induced $>2$-fold increase in RunX2 mRNA expression in MC3T3-E1 cells; however, MGF did not affect the level of RunX1 mRNA expression (Fig. 2A and B).

Effects of mangiferin on cell differentiation and gene expression regulation in osteoclast lineage cells. The effect of $10^{-3} \mathrm{M}$ MGF on osteoclast differentiation was determined. The number of TRAP-positive multinuclear cells were counted. MGF reduced the number of TRAP-positive multinuclear cells by $\sim 50 \%$ compared with the vehicle control (Fig. $3 \mathrm{~A}$ and B).

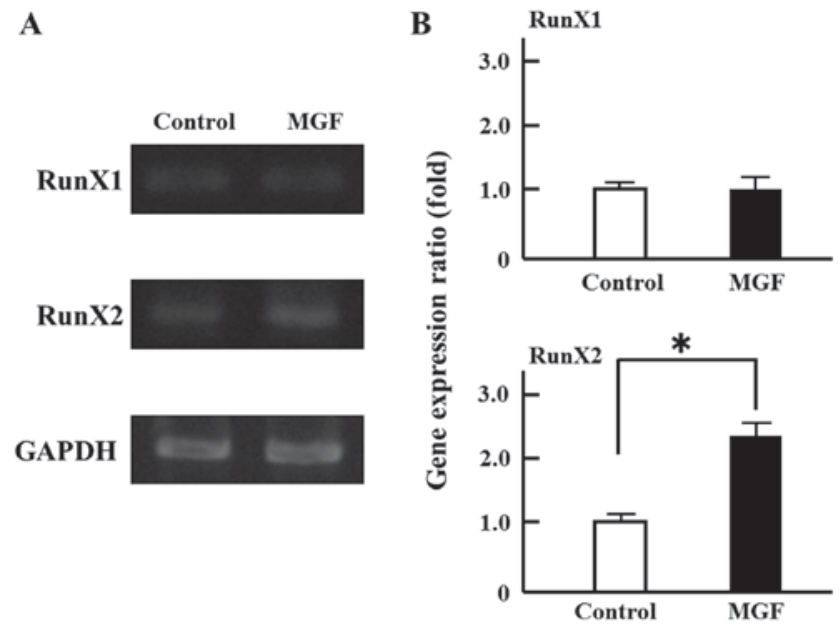

Figure 2. Effect MGF on gene expression related to osteoblast-regulated genes. (A) Total RNA extracted from MC3T3-E1 cells treated with or without MGF $\left(10^{-3} \mathrm{M}\right)$ for $2 \mathrm{~h}$. mRNA expression of RunX1 and RunX2 were analyzed by reverse transcription-polymerase chain reaction. (B) The semi-quantitative results are expressed as the mean \pm standard deviation of three independent experiments $(n=3)$. ${ }^{*} \mathrm{P}<0.05$. MGF, mangiferin; RunX, runt related transcription factor.
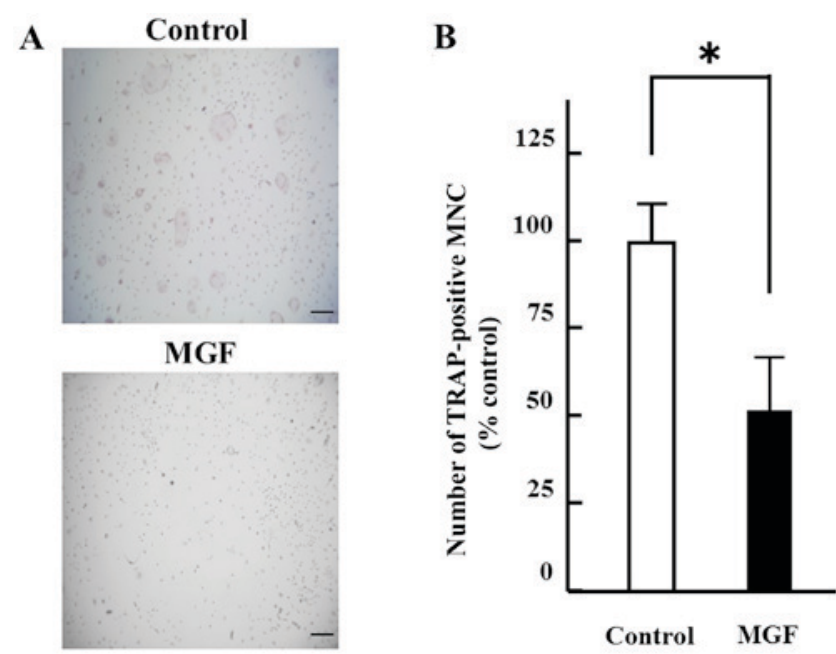

Figure 3. Effect of MGF on TRAP-positive MNCs formation from BMM cells. (A) Mouse BMM cells were treated with or without $\mathrm{MGF}\left(10^{-3} \mathrm{M}\right)$ in the presence of macrophage colony stimulating factor $(20 \mathrm{ng} / \mathrm{ml})$ and receptor activator nuclear factor- $\kappa \mathrm{B}$ ligand $(10 \mathrm{ng} / \mathrm{ml})$. TRAP staining was performed to determine the effect on osteoclast formation. After 6 days of incubation, the cells were subjected to TRAP staining and compared with osteoclast-like cells (control). (B) The results are expressed as the mean \pm standard deviation of three independent experiments $(\mathrm{n}=3)$. Scale bar, $100 \mu \mathrm{m}$; original magnification, $\mathrm{x} 200 .{ }^{*} \mathrm{P}<0.05$. MGF, mangiferin; TRAP, tartrate-resistant acid phosphatase; MNCs, multinuclear cells; BMM, bone marrow macrophage.

Regarding the effect of MGF on the expression of genes involved in the differentiation of osteoclasts, the cathepsin $\mathrm{K}$ and OSCAR mRNA expression in BMM cells was $\sim 1 / 4$ of that in OCLs; RANK was two-fold higher and ER $\alpha$ was 4-fold higher in BMM cells compared with mature OCL cells (Fig. 4A and 4B). In addition, MGF treatment increased the ER $\beta$ mRNA expression level in BMM by $\sim 5$-fold compared with untreated BMM. However, MGF did not affect the expression levels of cathepsin K, c-fos, ER $\alpha, N_{F}-\kappa B, N F A T c 1$, OSCAR or RANK mRNA in BMM. 
A

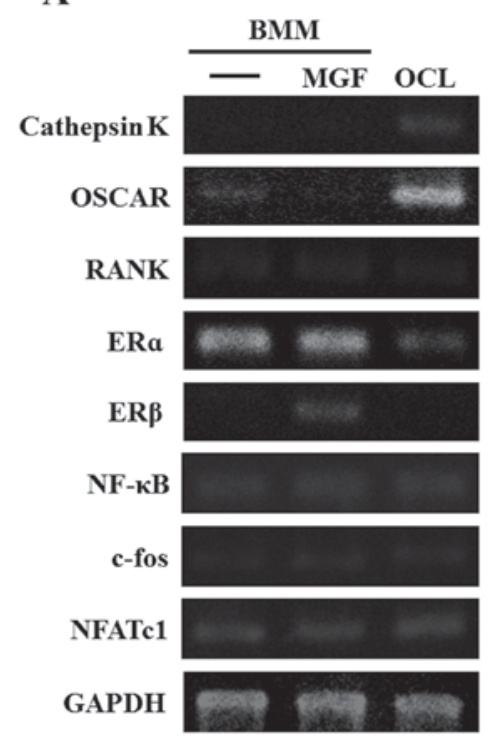

B

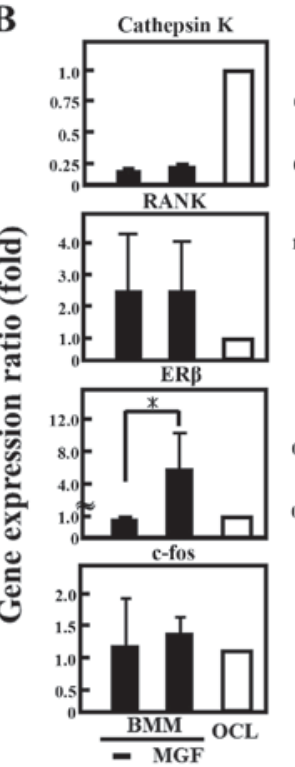

OSCAR
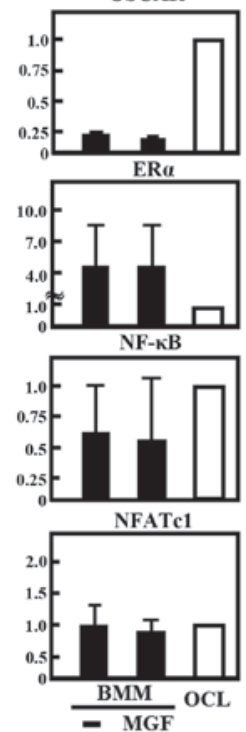

Figure 4. Effect of MGF on gene expression of osteoclast-associated genes. (A) The mRNA expression of cathepsin K, OSCAR, RANK, ER $\alpha$, ER $\beta$, NF- $\kappa B$, c-fos, and NFATc1 were analyzed by reverse transcription-polymerase chain reaction. Total RNA extracted from control OCL in the presence of macrophage colony stimulating factor $(20 \mathrm{ng} / \mathrm{ml})$ and RANK ligand $(10 \mathrm{ng} / \mathrm{ml})$ for 3 days and BMM cells treated with or without MGF (10 $\left.{ }^{-3} \mathrm{M}\right)$ for $3 \mathrm{~h}$. (B) The results are expressed as the mean \pm standard deviation of three independent experiments $(n=3)$. ${ }^{*}<0.05$. BMM, bone marrow macrophages; MGF, mangiferin; OCL, osteoclast-like cells; OSCAR, osteoclast-associated receptor; RANK, receptor activator nuclear factor- $\kappa \mathrm{B}$; ER, estrogen receptor; NF- $\kappa \mathrm{B}$, nuclear factor- $\kappa \mathrm{B}$; NFATc1, nuclear factor of activated T-cells, cytoplasmic 1.

\section{Discussion}

The present study aimed to investigate whether MGF affects cell proliferation, cell differentiation and gene expression in cultured osteoblasts and osteoclasts. For example, $\alpha$-mangostin, a compound similar to MGF, has been reported to affect cell proliferation in human lung adenocarcinoma cells and human breast adenocarcinoma cells $(25,26)$. The present study indicated that MGF may promote cell proliferation and cell differentiation of osteoblasts. Furthermore, MGF may induce osteoblast differentiation from preosteoblasts to mature osteoblasts via RunX2. It is established that RunX1 regulates the differentiation of hematopoietic stem cells, and that RunX2 regulates the differentiation of osteoblasts $(27,28)$. Additionally, Runx 2 and ALP are validated osteoblastic differentiation markers (29-31). The results of the present study indicated that MGF may inhibit M-CSF- and RANKL-induced osteoclast formation and differentiation from BMM to TRAP-positive multinuclear cells as osteoclasts. These results indicate that MGF suppressed the differentiation of osteoclasts from BMM and promoted the expression of ER $\beta$ mRNA in BMM. These data suggest that MGF ay suppress osteoclastogenesis via the ER $\beta$ signal. In conventional investigation of osteoclasts, the effect on TRAP-positive cells indicates the induction of differentiation of osteoclasts $(32,33)$. In addition, it is established that ER suppresses osteoclastogenesis $(34,35)$.

In conclusion, MGF promoted cell proliferation and induced cell differentiation in preosteoblast MC3T3-E1 cells via RunX2; thus, MGF may potentially promote osteoblastic bone formation. MGF suppressed cell differentiation to mature OCL, and promoted the mRNA expression of ER $\beta$ in BMM; thus, MGF may potentially inhibit osteoclastic bone resorption. MGF may adjust the balance between osteoblast and osteoclast function, and could be useful in improving bone diseases. Further study is warranted into the use of MGF as a treatment for bone diseases such as osteoporosis, osteopetrosis and RA.

\section{References}

1. Makare N, Bodhankar S and Rangari V: Immunomodulatory activity of alcoholic extract of Mangifera indica L. In mice. J Ethnopharmacol 78: 133-137, 2001.

2. Yoshikawa M, Ninomiya K, Shimoda $\mathrm{H}$, Nishida $\mathrm{N}$ and Matsuda $\mathrm{H}$ : Hepatoprotective and antioxidative properties of Salacia reticulata: Preventive effects of phenolic constituents on CCl4-induced liver injury in mice. Biol Pharm Bull 25: 72-76, 2002.

3. Guha S, Ghosal S and Chattopadhyay U: Antitumor, immunomodulatory and anti-HIV effect of mangiferin, a naturally occurring glucosylxanthone. Chemotherapy 42: 443-451, 1996.

4. Sánchez GM, Re L, Giuliani A, Núñez-Sellés AJ, Davison GP and León-Fernández OS: Protective effects of Mangifera indica L. Extract, mangiferin and selected antioxidants against TPA-induced biomolecules oxidation and peritoneal macrophage activation in mice. Pharmacol Res 42: 565-573, 2000.

5. Feng J, Yang XW and Wang RF: Bio-assay guided isolation and identification of $\alpha$-glucosidase inhibitors from the leaves of Aquilaria sinensis. Phytochemistry 72: 242-247, 2011.

6. Im R, Mano H, Matsuura T, Nakatani S, Shimizu J and Wada M: Mechanisms of blood glucose-lowering effect of aqueous extract from stems of Kothala himbutu (Salacia reticulata) in the mouse. J Ethnopharmacol 121: 234-240, 2009.

7. Sekiguchi Y, Mano H, Nakatani S, Shimizu J and Wada M: Effects of the Sri Lankan medicinal plant, Salacia reticulata, in rheumatoid arthritis. Genes Nutr 5: 89-96, 2010.

8. Ang E, Liu Q, Qi M, Liu HG, Yang X, Chen H, Zheng MH and $\mathrm{Xu} \mathrm{J}$ : Mangiferin attenuates osteoclastogenesis, bone resorption, and RANKL-induced activation of NF- $\kappa \mathrm{B}$ and ERK. J Cell Biochem 112: 89-97, 2011.

9. Zhao B, Takami M, Yamada A, Wang X, Koga T, Hu X, Tamura T, Ozato K, Choi Y, Ivashkiv LB, et al: Interferon regulatory factor- 8 regulates bone metabolism by suppressing osteoclastogenesis. Nat Med 15: 1066-1071, 2009. 
10. Soysa NS, Alles N, Weih D, Lovas A, Mian AH, Shimokawa H, Yasuda H, Weih F, Jimi E, Ohya K and Aoki K: The pivotal role of the alternative NF-kappaB pathway in maintenance of basal bone homeostasis and osteoclastogenesis. J Bone Miner Res 25 809-818, 2010

11. Childress P, Philip BK, Robling AG, Bruzzaniti A, Kacena MA Bivi N, Plotkin LI, Heller A and Bidwell JP: Nmp4/CIZ suppresses the response of bone to anabolic parathyroid hormone by regulating both osteoblasts and osteoclasts. Calcif Tissue Int 89: 74-89, 2011.

12. Funk JL, Cordaro LA, Wei H, Benjamin JB and Yocum DE: Synovium as a source of increased amino-terminal parathyroid hormone-related protein expression in rheumatoid arthritis. A possible role for locally produced parathyroid hormone-related protein in the pathogenesis of rheumatoid arthritis. J Clin Invest 101: 1362-1371, 1998.

13. Parekh RB, Dwek RA, Sutton BJ, Fernandes DL, Leung A, Stanworth D, Rademacher TW, Mizuochi T, Taniguchi T, Matsuta K, et al: Association of rheumatoid arthritis and primary osteoarthritis with changes in the glycosylation pattern of total serum IgG. Nature 316: 452-457, 1985.

14. Steinitz M, Izak G, Cohen S, Ehrenfeld M and Flechner I: Continuous production of monoclonal rheumatoid factor by EBV-transformed lymphocytes. Nature 287: 443-445, 1980

15. Ainola M, Li TF, Mandelin J, Hukkanen M, Choi SJ, Salo J and Konttinen YT: Involvement of a disintegrin and a metalloproteinase 8 (ADAM8) in osteoclastogenesis and pathological bone destruction. Ann Rheum Dis 68: 427-434, 2009.

16. Boyle WJ, Simonet WS and Lacey DL: Osteoclast differentiation and activation. Nature 423: 337-342, 2003.

17. Rudge S, Hailwood S, Horne A, Lucas J, Wu F and Cundy T: Effects of once-weekly oral alendronate on bone in children on glucocorticoid treatment. Rheumatology (Oxford) 44: 813-818, 2005.

18. Hansen IB, Ellingsen T, Hornung N, Poulsen JH, Lottenburger T and Stengaard-Pedersen K: Plasma level of CXC-chemokine CXCL12 is increased in rheumatoid arthritis and is independent of disease activity and methotrexate treatment. J Rheumatol 33 1754-1759, 2006

19. Puéchal X, Miceli-Richard C, Mejjad O, Lafforgue P, Marcelli C, Solau-Gervais E, Steinfeld S, Villoutreix C, Trèves R, Mariette X, et al: Anti-tumour necrosis factor treatment in patients with refractory systemic vasculitis associated with rheumatoid arthritis. Ann Rheum Dis 67: 880-884, 2008.

20. Lories R: The balance of tissue repair and remodeling in chronic arthritis. Nat Rev Rheumatol 7: 700-707, 2011.

21. Luppen CA, Blake CA, Ammirati KM, Stevens ML, Seeherman HJ, Wozney JM and Bouxsein ML: Recombinant human bone morphogenetic protein-2 enhances osteotomy healing in glucocorticoid-treated rabbits. J Bone Miner Res 17: 301-310, 2002

22. Li J, Mashiba T and Burr DB: Bisphosphonate treatment suppresses not only stochastic remodeling but also the targeted repair of microdamage. Calcif Tissue Int 69: 281-286, 2001.

23. Gruber CJ, Tschugguel W, Schneeberger C and Huber JC: Production and actions of estrogens. N Engl J Med 346: 340-352, 2002.
24. Mano H, Hakeda Y and Kumegawa M: Estrogen directly down-regulates the bone-resorbing activity of mature osteoclasts through nuclear estrogen receptor alpha. Cytotechnology 35: $17-23,2001$.

25. Shih YW, Chien ST, Chen PS, Lee JH, Wu SH and Yin LT: Alpha-mangostin suppresses phorbol 12-myristate 13-acetate-induced MMP-2/MMP-9 expressions via alphavbeta3 integrin/FAK/ERK and NF-kappaB signaling pathway in human lung adenocarcinoma A549 cells. Cell Biochem Biophys 58: 31-44, 2010.

26. Lee YB, Ko KC, Shi MD, Liao YC, Chiang TA, Wu PF, Shih YX and Shih YW: Alpha-mangostin, a novel dietary xanthone, suppresses TPA-mediated MMP-2 and MMP-9 expressions through the ERK signaling pathway in MCF-7 human breast adenocarcinoma cells. J Food Sci 75: H13-H23, 2010.

27. Ichikawa M, Goyama S, Asai T, Kawazu M, Nakagawa M, Takeshita M, Chiba S, Ogawa S and Kurokawa M: AML1/Runx1 negatively regulates quiescent hematopoietic stem cells in adult hematopoiesis. J Immunol 180: 4402-4408, 2008.

28. Liu JC, Lengner CJ, Gaur T, Lou Y, Hussain S, Jones MD, Borodic B, Colby JL, Steinman HA, van Wijnen AJ, et al: Runx2 protein expression utilizes the Runx2 P1 promoter to establish osteoprogenitor cell number for normal bone formation. J Biol Chem 286: 30057-30070, 2011

29. Jang WG, Kim EJ, Bae IH, Lee KN, Kim YD, Kim DK, Kim SH, Lee CH, Franceschi RT, Choi HS and Koh JT: Metformin induces osteoblast differentiation via orphan nuclear receptor SHP-mediated transactivation of Runx2. Bone 48: 885-893, 2011.

30. Laflamme C, Curt S and Rouabhia M: Epidermal growth factor and bone morphogenetic proteins upregulate osteoblast proliferation and osteoblastic markers and inhibit bone nodule formation. Arch Oral Biol 55: 689-701, 2010.

31. Lim TY, Wang W, Shi Z, Poh CK and Neoh KG: Human bone marrow-derived mesenchymal stem cells and osteoblast differentiation on titanium with surface-grafted chitosan and immobilized bone morphogenetic protein-2. J Mater Sci Mater Med 20: 1-10, 2009.

32. Teramachi J, Morimoto H, Baba R, Doi Y, Hirashima K and Haneji T: Double stranded RNA-dependent protein kinase is involved in osteoclast differentiation of RAW264.7 cells in vitro. Exp Cell Res 316: 3254-3262, 2010.

33. Takayanagi H, Kim S, Koga T, Nishina H, Isshiki M, Yoshida $H$, Saiura A, Isobe M, Yokochi T, Inoue J, et al: Induction and activation of the transcription factor NFATc1 (NFAT2) integrate RANKL signaling in terminal differentiation of osteoclasts. Dev Cell 3: 889-901, 2002.

34. Windahl SH, Norgård M, Kuiper GG, Gustafsson JA and Andersson G: Cellular distribution of estrogen receptor beta in neonatal rat bone. Bone 26: 117-121, 2000.

35. Hiyama S, Sugiyama T, Kusuhara S and Uchida T: Evidence for estrogen receptor expression during medullary bone formation and resorption in estrogen-treated male Japanese quails (Coturnix coturnix japonica). J Vet Sci 13: 223-227, 2012. 